Geopolítica(s) Revista de estudios sobre espacio y poder ISSN: 2172-3958

http://dx.doi.org/10.5209/GEOP.60708

\title{
Transformar la ciudad para cambiar la vida
}

Santiago de Miguel Salanova (2017) Republicanos y socialistas. El nacimiento de la acción política municipal en Madrid (1891-1909). Madrid: Los libros de la Catarata, 175 pp. ISBN: 978-84-9097-268-7.

Uno de los elementos fundamentales en la gestión municipal es la toma de conciencia de la relación existente entre la intervención urbana y la mejora de las condiciones sociales de la población. Los procesos de planificación urbana, los proyectos y la elección de las políticas municipales que inciden en la construcción de las ciudades no son elementos técnicos, neutrales y carentes de una intencionalidad política. La ciudad se hace con una intención, en una determinada dirección y configurando una forma concreta de la misma que se interrelaciona con la calidad de vida de los vecinos, los desequilibrios territoriales y con el incremento o disminución de la desigualdad social. Sobre estos ejes gira esta obra, analizando el momento en el que la conexión entre estas ideas apareció en Madrid.

Santiago de Miguel Salanova realiza un recorrido por la historia de la irrupción de los primeros concejales republicanos y socialistas en el Ayuntamiento de Madrid. Este libro, galardonado en 2016 con el Premio de Investigación de la Asociación de Historia Social, se centra en analizar el cambio de actitudes, la aparición de nuevas demandas y el intento de transformación estructural que estos primeros concejales supusieron para la vida del consistorio madrileño. Así, se pone de manifiesto la importancia que a partir de un determinado tiempo adquirió la política municipal dentro de las concepciones políticas de ciertos grupos que hasta ese momento no habían podido entrar a formar parte de las estancias institucionales. De esta manera, para estos grupos, la política urbana y municipal se convirtió en el eje alrededor del cual giraba su participación en el Ayuntamiento, institución que hasta ese momento había servido más a los intereses particulares de los ediles que a los intereses sociales de los madrileños.

A lo largo de seis capítulos, el autor recorre diversas temáticas orientadas a mostrar la situación de la ciudad de Madrid a finales del s. XIX y principios del s. XX. Entre ellas destacan una descripción del Madrid de la época poniendo énfasis en los desequilibrios territoriales y sociales existentes, la falta de iniciativa municipal para solucionarlos, el nepotismo y el clientelismo que existía en el Ayuntamiento, las deficiencias sanitarias y alimentarias que asolaban Madrid a través de hambrunas, productos encarecidos y epidemias, la escasez de políticas concretas que pudieran paliar sus efectos, las dificultades de la ciudad para hacer frente a la 
llegada de población que fuera absorbida por el mercado laboral, los efectos que las transformaciones urbanas habían provocado ${ }^{1}$ y la segregación territorial que provocaba la orientación de las políticas municipales hacia el centro urbano y el abandono de la periferia. Contra esta situación generalizada se centró el trabajo de los ediles republicanos y socialistas que habían entendido la necesidad de una política urbana que diera solución a las dificultades de los más desfavorecidos.

Como ya señalaron autores como David Harvey, la forma en la que está modelado - y se modela - el espacio urbano tiene profundos efectos sobre los procesos sociales. En una continua interacción dinámica entre espacio y procesos sociales que se debe entender en una interrelación constante alejada de los determinismos ${ }^{2}$. La ciudad de Madrid había cambiado a lo largo del s. XIX, tanto a nivel demográfico, social como urbano, y esto suponía la necesidad de pensar la ciudad de una manera diferente (p. 21). Las medidas que a lo largo de la últimas décadas del s. XIX se habían ido adoptando desde el consistorio madrileño no sólo no habían respondido a las necesidades sociales de los madrileños sino que habían profundizado un fuerte desequilibrio territorial que marcaba la configuración urbana. A lo largo de la obra, el autor nos muestra con diferentes datos, tablas y mapas los desequilibrios existentes entre los diez distritos administrativos que existían en la capital. Así se muestra, entre otros datos, la desigualdad en las tasas de mortalidad por las epidemias (p. 102), la densidad de población desequilibrada entre barrios que estaba relacionada con el precio de los alquileres (p. 110) y la distribución del voto por distritos poniendo de relieve fronteras de preferencias electorales (p. 20). Para recomponer la administración de la ciudad los programas republicanos y socialistas incluyeron la necesidad de medidas para la supresión de los impuestos más gravosos para la clase trabajadora, la jornada de ocho horas y la subida del salario, la mejora y eficiencia en los sistemas de contratación pública que evitaran las redes clientelares, la creación de asilos, el control higiénico de los alimentos y las mejoras sanitarias fundamentales para evitar las epidemias recurrentes y los focos infecciosos. Como señala el autor estas medidas se basaban en la toma de conciencia por los ediles socialistas madrileños de la íntima conexión entre las políticas municipales y la realidad cotidiana de las clases populares más desfavorecidas (p. 31). Por lo tanto, se trataba de medidas que permitían una mejor distribución de los servicios sociales, una mejora de la calidad de vida y una redistribución de la riqueza entre distritos para evitar el desequilibrio que había forjado una división social, económica y de salubridad entre el centro y la periferia. Una serie de medidas e iniciativas que se nos presentan en la obra haciendo hincapié en la relación entre los proyectos urbanos y las políticas sociales. Con todo esto, en muchos casos el análisis se acerca a los estudios que se han agrupado dentro de la denominada Geografía del Bienestar, preocupada por el hambre, la discriminación y el acceso a los servicios sociales ${ }^{3}$, aunque el análisis del autor se centra en la perspectiva histórica.

\footnotetext{
Para saber más sobre estas transformaciones urbanas durante el siglo XIX, ver Rubén Pallol Trigueros: Una ciudad sin límites. Transformación urbana, cambio social y despertar político en Madrid (1860-1875), Madrid, Los libros de Catarata, 2013.

David Harvey: Urbanismo y desigualdad social, Madrid, Siglo XXI, 1997, p. 17.

3 Ron Johnston et.al.: Diccionario AKAL de Geografia Humana, Madrid, AKAL, 2000, p. 254.
} 
Algo que la obra también nos permite conocer es que los proyectos urbanísticos más destacables de la época, como fue el caso de la construcción de la Gran Vía, tenían un efecto directo sobre la estructura socioeconómica de la ciudad. Ya no se trataba de la dejadez de los políticos municipales de la época del turnismo o de políticas orientadas a beneficiar determinados sectores y privilegiar ciertos distritos, se trataba, en este caso, de un proyecto de reforma urbanística cuya ejecución marcaba claras divisiones sociales entre zonas y marcaba a futuro la política urbana de la ciudad. La Gran Vía se convertía en ese momento en una clara frontera urba$\mathrm{na}^{4}$ - junto con la Puerta del Sol y la calle Atocha- y debían entenderse, en palabras del autor, "las consecuencias que esa obra tendría para la ciudad ampliando las diferencias sociales entre un centro urbano que fue adoptando un tono financiero, un Ensanche que se convirtió en punto de referencia para las clases bajas y medias y un extrarradio que quedó como refugio de los grupos con menos poder adquisitivo" (p. 105). Con esto se puede ver cómo los proyectos urbanos y la forma en la que se produce el espacio, no son elementos inocentes y técnicos, tienen consecuencias directas y están marcados por una clara intencionalidad. Esta orientación y el marcado carácter ideológico de las propuestas políticas municipales del momento que analiza la obra se aprecia claramente cuando expone la vinculación de las iniciativas de los ediles socialistas con sus ideas transformadoras. Para ellos, mejorar la ciudad era mejorar las condiciones de vida de la clase trabajadora; acabar con los fraudes alimentarios y los impuestos elevados sobre bienes de primera necesidad era acabar con los problemas de malnutrición que afectaban a las clases populares, y la lucha contra la pobreza y la insalubridad suponía una lucha contra el sistema que empobrecía al proletariado. Por lo tanto, desde un lado y otro se oponían dos modelos distintos de ciudad, de construir Madrid, que estaban directamente relacionados con dos modelos de construcción de la sociedad. De esta manera, si analizamos la obra desde una perspectiva geográfica y espacial, se nos pone de manifiesto la concepción política del espacio como algo atravesado por la ideología y el conflicto, no dado a priori, no neutral, sino representado previamente con la intención de ser entendido de manera normativa ${ }^{5}$.

Las actuaciones de estos ediles permitieron la formación de una nueva mayoría tras las elecciones de 1909. Un cambio en la dinámica política de la época de la Restauración que ponía de manifiesto la toma de conciencia de los vecinos madrileños de los efectos de las políticas municipales sobre sus vidas. El libro cierra marcando el carácter pionero que tuvieron esos primeros concejales republicanos y socialistas que introdujeron una nueva forma de entender Madrid, de entender la labor municipal y de concebir las políticas públicas a desarrollar.

A través de las páginas de la obra, el autor, aunque su enfoque sea disciplinar y eminentemente histórico, nos permite ver la compleja relación existente entre espacio y procesos sociales evidenciando la imposibilidad de entender la misma desde la unidireccionalidad. La configuración del espacio afecta a los procesos sociales, por ejemplo en el caso de los efectos de proyectos urbanos como el de la Gran Vía, pero también los procesos sociales, como las hambrunas, las epidemias y el creci-

4 Neil Smith: La nueva frontera urbana. Ciudad revanchista y gentrificación, Madrid, Traficantes de Sueños, 2012, p. 46.

5 Henri Lefebvre: "Reflections on the politics of space”, Antipode, vol. 2, núm. 8, 1976, p. 30-37. 
miento demográfico, tienen efectos directos sobre el espacio y la forma en la que éste se proyecta. Todo en una constante interrelación que continúa construyendo la ciudad de Madrid.

Sergio Claudio González García Facultad de Ciencias Políticas y Sociología, Universidad Complutense de Madrid Email: segonz01@ucm.es 